\title{
Do microvesicles derived from adipose mesenchymal stem cells have a therapeutic potential on Escherichia coli lipopolysaccharides- induced sepsis in Zona fasciculata of adult male albino rats? A Original histological study Article

\author{
Abeer I. Omar and Alshaymaa G. Aboulkhair \\ Department of Medical Histology and Cell Biology, Faculty of Medicine, Cairo University, \\ Cairo, Egypt
}

\begin{abstract}
Introduction: Sepsis is a major health problem with high mortality rate, despite advanced medications. Although hypothalamic-pituitary-adrenal (HPA) axis activation can control its destructive inflammatory reactions, adrenal insufficiency (AI) is commonly associated with it. Mesenchymal Stem Cell-Derived Microvesicles (MSCs-MVs) were proved to be as effective as their origin cells in tissue repair.

Aim of the work: To study the effects of Escherichia coli-lipopolysaccharides (E. coli-LPS) induced sepsis on Zona fasciculata of adult male albino rats and probable therapeutic effects of adipose derived mesenchymal stem cells-microvesicles (ADMSCs-MVs).

Materials and Methods: Forty-four adult male albino rats were divided into three groups; (I) the controls, (II) LPS and (III) MV. Sepsis was induced in LPS and MV-groups using E. coli-LPS. Four hours later, MV-group received single intravenous (IV) injection of PKH26 labelled ADMSCs-MVs. All animals were sacrificed 48 hours after ADMSCs-MVs administration. Tumor necrosis factor- $\alpha$ (TNF- $\alpha)$, cyclo-oxygenase-2 (COX-2) and nitric oxide (NO) levels were measured in adrenal homogenates of each group. Sections from all groups were subjected to H\&E, besides, immunohistochemical stains for CD44, inducible nitric oxide synthase (iNOS) and proliferating cell nuclear antigen (PCNA). Unstained sections of subgroup IC and MV-group were examined by fluorescent microscope. Mean number of CD44 and PCNA positive cells and mean area percent of iNOS immunoreaction were measured and data were statistically analyzed.

Results: LPS-group showed non-survivors (24 hours after LPS-injection) and survivors with features of Zona fasciculata inflammatory damage, besides increased TNF- $\alpha$ and NO and decreased COX-2. The MV-group revealed marked increase in CD44 and PCNA, but significant decrease in iNOS immunoreactions. Additionally, ADMSCs-MV homing was detected in Zona fasciculata.

Conclusion: LPS-induced sepsis caused marked Zona fasciculata inflammatory degeneration improved by ADMSCs-MVs single IV injection; mostly through transfer of proteins, mRNA, microRNA and/or organelles with reparative functions from ADMSCs to the injured tissues.
\end{abstract}

Received: 15 January 2018, Accepted: 24 February 2018

Key Words: ADMSCs-MV, CD44, COX-2, iNOS, sepsis, Zona fasciculata

Corresponding Author: Abeer I. Omar, Department of Medical Histology and Cell Biology, Faculty of Medicine, Cairo University, Cairo, Egypt, Tel.: 00201002596677, E-mail: kaboree2002@gmail.com

ISSN: 1110-0559, Vol. 41, No.2

\section{INTRODUCTION}

Sepsis is a worldwide health problem associate with increased mortality specially in the intensive care unit even with the use of advanced medications ${ }^{[1,2]}$. The mortality rate from sepsis was reported to increase from $25 \%$ to $70 \%$ when it is complicated by multi-organ failure and septic $\operatorname{shock}^{[3]}$.

Sepsis is characterized by irresistible inflammatory response to infections which could not be controlled by the body ${ }^{[4]}$. Thus, it results into induction of stress response through activation of hypothalamic-pituitary-adrenal axis (HPA axis). Such stimulation of the suprarenal cortex, especially the Zona fasciculata, leads to secretion of large amount of cortisol with its anti-inflammatory, immunomodulatory and homeostatic effects ${ }^{[5]}$. So, intact stress and suprarenal responses are essentials to survive $\operatorname{sepsis}^{[6]}$.

This HPA axis is commonly affected in sepsis, resulting in AI that is characterized by low cortisol production either directly or indirectly through adrenocortical hyporesponsiveness to pituitary ACTH stimulation ${ }^{[7]}$. Such 
low cortisol level increases the vasopressors need and the mortality rate due to its progression to septic shock and multi-organ failure ${ }^{[8]}$.

The newest international guidelines for managing severe sepsis suggested the use of cortisone, especially in patients with poor response to fluid restoration and vasopressors. However, the corticosteroid supplementation is markedly restricted by the unpleasant effects of cortisol such as insulin resistance, suppression of immune response and protein catabolism ${ }^{[9]}$. Therefore, a new efficient and unharmed management for adrenal insufficiency in septic patients is needed.

Microvesicles (MVs) are $50 \mathrm{~nm}$ to $1 \mu \mathrm{m}$ non-nucleated membrane bound fragments, released as exosomes from the endosomal system or discarded from surface membrane of multiple cell types. They are spheroid particles enclosing proteins, lipids, organelles, mRNAs and microRNAs similar to the cells from which they are derived ${ }^{[10,11]}$.

Mesenchymal stem cells' MVs were evidenced to be as effectual as the cells themselves in restoring injured tissues. They home in the site of lesion then, they are engulfed by the injured cells via receptor-mediated endocytosis $\left.^{[1,12,} 13\right]$ transferring the stem cells' cellular contents (proteins, lipids, organelles, mRNAs and microRNAs) to these cells ${ }^{[11,14]}$.

This study aimed to investigate the effect of sepsis induced by $\mathrm{E}$. coli-LPS on the adrenal cortex' Zona fasciculata in adult male albino rats and the probable therapeutic effect of ADMSCs-MVs.

\section{MATERIALS AND METHODS}

\section{Animals}

Forty-four adult male albino rats, weighed $200-250 \mathrm{~g}$, were used in this study. They were housed in the Animal House, Faculty of Medicine, Cairo University. The rats were treated according to the guidelines approved by the Animal Use Committee of Cairo University. Rats were provided with ordinary rat chow, bred and housed in wire mesh cages at temperature $\left(24 \pm 1^{\circ} \mathrm{C}\right)$, with normal light/dark cycle. All animals were kept under the same environmental conditions and had free access to water and food.

\section{Chemicals}

-Lipopolysaccharide (LPS) extracted from the membrane of E. coli (coli 0127: B8, L3129) was purchased from Sigma-Aldrich, St Louis MO 63103, USA. It was dissolved in sterile pyrogen-free saline immediately before its use.

\section{-Chemicals for immunostaining:}

Primary antibodies:

a) CD44 antibody [rabbit polyclonal antibody] (Abcam, catalogue number ab157107).

b) iNOS antibody[rabbit polyclonal antibody] (Lab Vision Corporation Laboratories, catalogue number PA1-036).

c) PCNA antibody [rabbit polyclonal antibody] (Lab Vision Corporation Laboratories, catalogue number PA527214).

Citrate buffer (cat no AP 9003), Ultravision detection system (biotin-streptavidin detection system, cat no TP 015- HD) and Mayer's hematoxylin (cat no TA- 060- MH). All were purchased from Labvision Thermoscientific, USA.

\section{Preparation of PKH26 labelled ADMSCs-MVs}

Allogenic PKH26 labelled rat ADMSCs-MVs were purchased from stem cell research unit at the Biochemistry Department, Faculty of Medicine, Cairo University, where they were prepared according to previously described methodology ${ }^{[15,16]}$.

\section{Experimental design:}

Forty-four adult male albino rats were divided into three groups:

Control group (group I, 12 rats): They were subdivided into three subgroups (4 rats each):

Subgroup IA: rats had free access to water and food without receiving any treatment.

Subgroup IB: animals were given single intravenous (IV) injection of $1 \mathrm{ml}$ saline via the tail vein.

Subgroup IC: the rats were treated as in subgroup IB. Four hours later, they were given single IV injection of

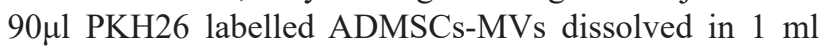
phosphate buffered saline (PBS).

LPS-group (group II, 20 rats): Sepsis is induced in the animals of this group using LPS extracted from E. coli.

MV-group (group III, 12 rats): Four hours after induction of sepsis as in group II, the rats of this group received single IV injection of $90 \mu$ of PKH26 labelled ADMSCs-MVs dissolved in $1 \mathrm{ml}$ PBS via tail vein ${ }^{[14]}$.

\section{Experimental procedure:}

\section{1- Induction of sepsis:}

Animals were given a single IV injection of $10 \mathrm{mg} /$ $\mathrm{kg}$ of LPS dissolved in $1 \mathrm{ml}$ sterile saline via the tail vein, immediately after its preparation in Biochemistry Department, Faculty of Medicine, Cairo University ${ }^{[17]}$.

The animals of the three groups were sacrificed 48 hours after IV administration of ADMSCs-MVs. Just before scarification the animals were anesthetized with intraperitoneal injection of ketamine $(90 \mathrm{mg} / \mathrm{kg}) / \mathrm{xylazine}$ $(15 \mathrm{mg} / \mathrm{kg})^{[18]}$. Both suprarenal glands of each rat were dissected. 


\section{2- Biochemical investigation:}

Both adrenals of two rats from each control subgroup and six rats from each experimental group were used for the biochemical analysis. The adrenal gland was separated from the surrounding adipose tissue, kept in micro-tube and homogenized. Enzyme-linked immunosorbent assay (ELISA) kits were used to measure TNF- $\alpha$ (rat TNF alpha ELISA Kit, ab46070, abcam, Cambridge, UK), COX-2 (anti-COX2 antibody, ab52237, abcam, Cambridge, UK) and NO (total nitric oxide and nitrate/nitrite parameter assay kit, SKGE001, R and D, Abingdon, UK). These parameters were measured in the supernatant of the centrifuged homogenates of each group at Biochemistry Department, Faculty of Medicine, Cairo University according to the manufacturer's instructions.

\section{3- Light microscopic studies:}

The suprarenal glands of the remaining rats of each control subgroup and experimental group were fixed in $10 \%$ formol saline and kept for 24 hours then processed to obtain Paraffin blocks. Paraffin sections 6 micrometres thick were cut and stained by:

- Hematoxylin and Eosin stains (H\&E) $)^{[19]}$.

- Immunohistochemical staining for: CD44, a marker for endogenous and exogenous mesenchymal stem cells and the microvesicles derived from them.

- iNOS, a marker for inflammation-induced nitric oxide synthesis.

- PCNA, marker for cell proliferation.

Immunostaining required pretreatment ${ }^{[20]}$, this was done by boiling for 10 minutes in $10 \mathrm{Mm}, \mathrm{pH} 6$ citrate buffer for antigen retrieval and leaving the sections to cool in room temperature for 20 minutes. Then, the sections were incubated for one hour with the primary antibodies. Immunostaining was completed by the use of Ultravision detection system and counterstaining was done using Mayer's hematoxylin.

\section{4- Fluorescent microscopic study:}

Unstained sections of Paraffin blocks of subgroup IC and group III were examined by fluorescent microscope to detect homing of PKH26 labelled ADMSCs-MVs.

\section{5-Morphometric study:}

It included measuring of:

- Mean number of CD44 immuno-positive cells in the zona fasciculata in CD44 immunostained sections at a magnification of $\times 200$.

- Mean area percent of iNOS immuno-expression in iNOS immunostained sections at a magnification of $\times 400$.

- Mean number of PCNA positive cells in PCNA immunostained sections at a magnification of $\times 400$.

All measurements were done in 10 non overlapping fields from different sections of each control subgroup and each experimental group. Image analysis was done using Leica microsystems LTD (DFC 295) software image analysis computer system (Germany) in Dentistry Research And Equipment Unit, Faculty of Dentistry, Cairo University.

\section{6- Statistical analysis}

The morphometric and biochemical measurements were expressed as mean \pm standard deviation (SD) and were analyzed statistically using the software "Statistics for windows SPSS" version 16. This was done using oneway analysis of variance ANOVA followed by "Tuckey" post hoc test. Results were considered significant when $P$ value was $<0.05^{[21]}$.

\section{RESULTS}

\section{A) General observation:}

Death of four rats in group II was detected 24 hours after LPS administration.

All control subgroups revealed similar biochemical and histological results. Thus, they were collectively referred to as control group (group I).

\section{B) Biochemical results and statistical analysis (Table 1):}

The mean values of TNF- $\alpha$ and NO were significantly increased in LPS-group (group II) versus groups I and III and non-significantly increased in group III compared to group I.

Moreover, there was significant increase in the mean value of COX-2 in MV-group (group III) compared to control and LPS-groups, besides non-significant increase in LPS-group than control group.

\section{C) Histological results:}

\section{1- Fluorescent microscopic results:}

Sections of the control subgroup IC showed absence of PKH26 labelled ADMSCs-MVs (Fig. 1a), while sections of MV-group revealed presence of these labelled MVs in the zona fasciculata (Fig. 1b).

\section{2- Light microscopic results:}

\section{- H\&E stained sections:}

Sections of the control group revealed normal histological structure of the suprarenal gland. It was formed of cortex and medulla and surrounded by connective tissue capsule. The sections showed that the adrenal cortex was composed of 3 zones: zona glomerulosa (outermost zone), zona fasciculata (middle zone) and zona reticularis (innermost zone). The zona fasciculata represented about $70 \%$ of the suprarenal cortex and consisted of rows of polyhedral cells (spongiocytes) separated by 
blood capillaries. These cells appeared with acidophilic vacuolated cytoplasm and central rounded vesicular nuclei and some of these cells were binucleated (Figs. 2a and 2b).

LPS-group's sections showed disorganization and marked vacuolations of the cells of zona fasciculata. The majority of these cells appeared with shrunken dark nuclei. Additionally, mononuclear infiltration including macrophages, haemorrhage and blood capillaries dilatation with disrupted basement membranes were noticed (Figs. $2 \mathrm{c}$ and $2 \mathrm{~d}$ ).

Sections of MV-group appeared with almost normal histological appearance except for the presence of few cytoplasmic vacuolations, dark nuclei and slight capillary dilatation (Fig. 2e).

\section{- Immunohistochemical results:}

\section{i) Immunohistochemical staining for CD44:}

In sections of group I, positive CD44 immunoreaction was shown in the cytoplasm of some of the adrenal medulla cells however, the steroidogenic cells of zona fasciculata showed no immunoreaction (Figs. 3a-3c). In group II, few CD44 immunoreaction was detected in the zona fasciculata (Fig. 3d) while, in group III multiple cells in the zona fasciculata appeared with positive cytoplasmic reaction (Fig. 3e).

ii) Immunohistochemical staining for PCNA:

PCNA immunoreactivity was noticed in very few nuclei of zona fasciculata in the control group (fig. 4a), however sections of LPS-group showed some cells with positive nuclear immunoreaction (Fig. 4b). The majority of the zona fasciculata cells of MV-group revealed positive nuclear immunoreaction in their nuclei (Fig. 4c).

iii) Immunohistochemical staining for iNOS:

No positive immunoreaction was detected in the sections of the control group (Fig. 5a). In LPS-group sections, multiple positive cytoplasmic immunoreactivity was distinguished in the endothelial and the inflammatory cells and not in the spongiocytes (Fig. 5b). However, in sections of MV-group very few endothelial cells showed weak positive immunoreaction (Fig. 5c).

\section{3- Morphometric results (Table 2):}

i) Mean number of CD44 immuno-positive cells in zona fasciculata:

It showed significant increase in group III versus group II.

ii) Mean number of PCNA immune-positive nuclei:

Group III demonstrated significant increase when compared to group II that revealed significant increase than group I.

iii) Mean area percent of iNOS immuno-positive cells:

There was significant decrease in iNOS mean area percent in MV-group compared to LPS-group.

Table 1: Mean values $( \pm \mathrm{SD})$ of tissue TNF- $\alpha, \mathrm{COX}-2$ and NO levels in the studied groups

\begin{tabular}{lccc}
\hline & Group I & Group II & Group III \\
Parameters & $5.2 \pm 0.21$ & $11.9 \pm 1.1^{*}$ & $5.7 \pm 0.17$ \\
$\mathrm{TNF}-\alpha(\mathrm{ng} / \mathrm{ml})$ & $1.2 \pm 0.35$ & $1.7 \pm 0.65$ & $6.2 \pm 1.24^{\#}$ \\
$\mathrm{COX}-2(\mathrm{ng} / \mathrm{ml})$ & $52.6 \pm 10.5$ & $132.3 \pm 25.5^{*}$ & $60.2 \pm 11.5$ \\
$\mathrm{NO}(\mu \mathrm{mol} / \mathrm{l})$ & & \\
\hline
\end{tabular}

* Increased significantly versus groups I and III ; ${ }^{\#}$ Increased significantly versus groups I and II.

Table 2: Mean values $( \pm \mathrm{SD})$ of morphometric parameters in the studied groups

\begin{tabular}{lccc}
\hline Parameters & Groups & Group I & Group II \\
\hline Mean number of CD44 & Not detected & $6.2 \pm 1.1$ & $25.2 \pm 5.2^{\sharp}$ \\
Mean number of PCNA & $2.20 \pm 0.05$ & $8.1 \pm 2.01^{\S}$ & $42.13 \pm 8.0^{5^{*}}$ \\
Mean area percent of iNOS immunoreaction & Not detected & $30.2 \pm 4.71$ & $5.2 \pm 0.3^{\square}$ \\
\hline
\end{tabular}

\# Increased significantly versus group II. ; * Increased significantly versus groups I \& II ; \$ Increased significantly versus group I. ; $\square$ Decreased significantly versus group II. 

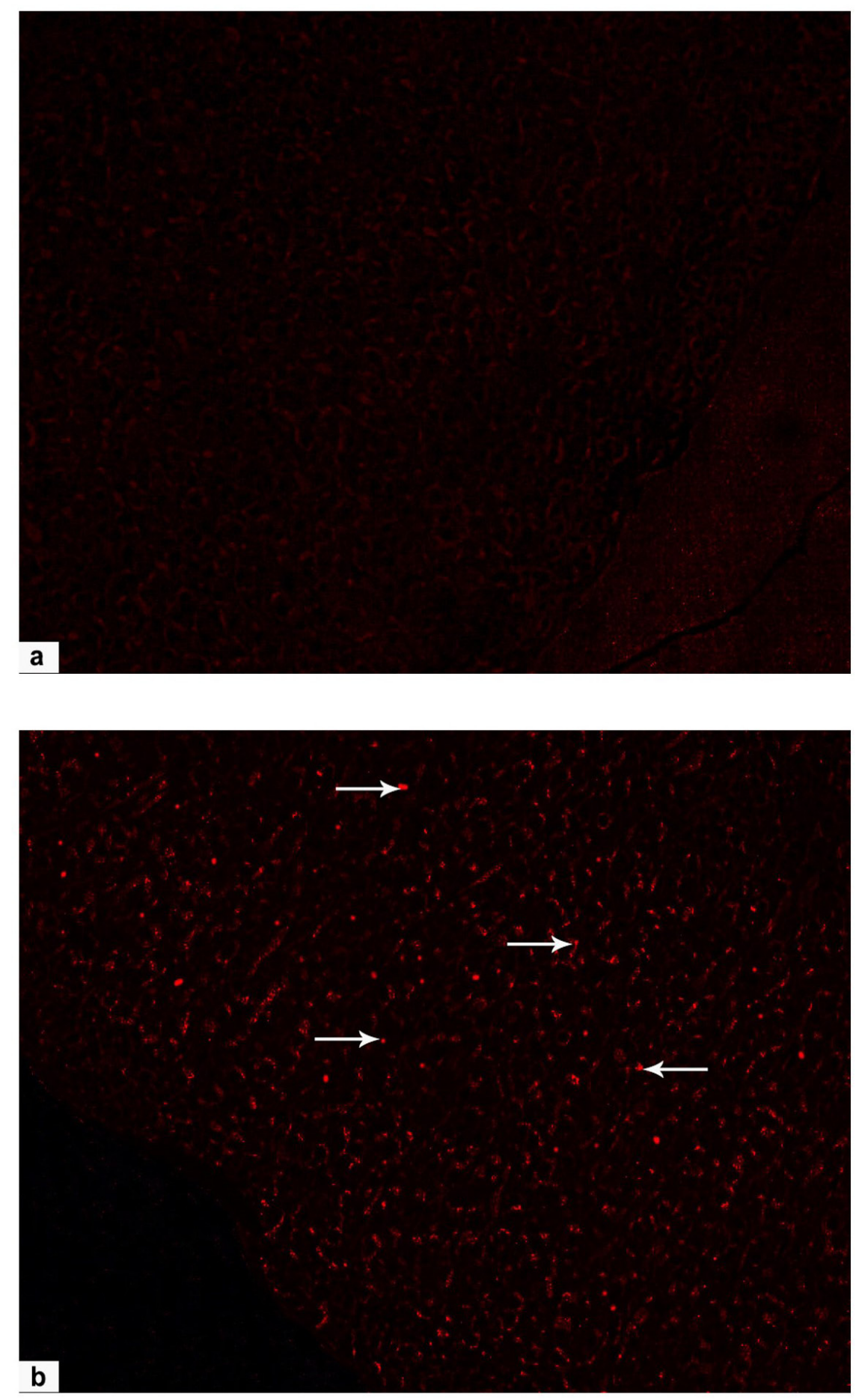

Fig. 1: Photomicrographs of sections in the suprarenal gland of albino rats showing: a: Absence of PKH26 labeled ADMSCs-MVs in the control subgroup IC. b: Presence of PKH26 labeled ADMSCs-MVs (arrows) in the Zona fasciculata in group III.

[Fluorescent microscope image, $x$ 200] 

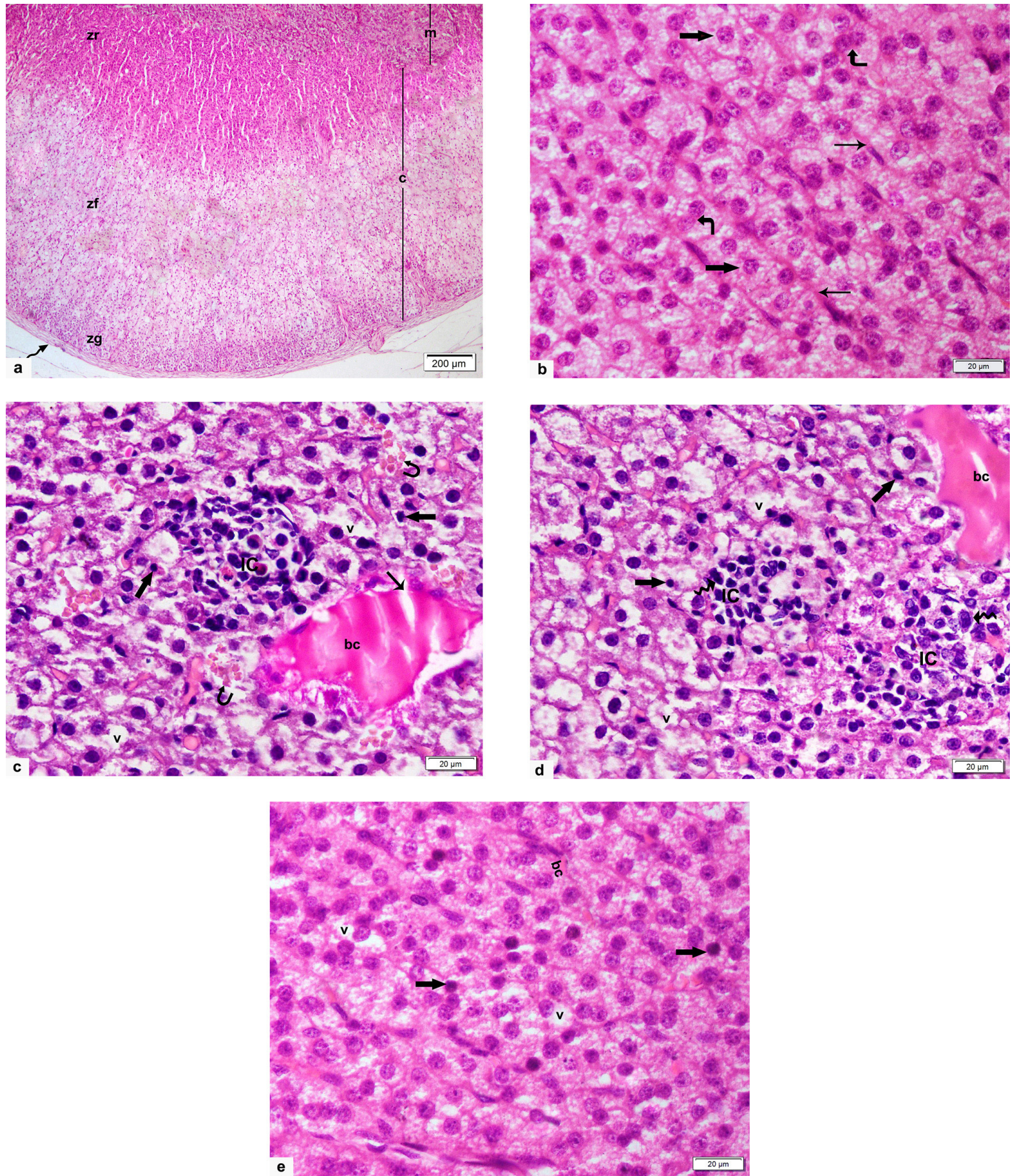

Fig. 2: Photomicrographs of sections in the rats' suprarenal gland: a: Control group shows cortex (c), medulla (m) and connective tissue capsule (wavy arrow). The cortex is composed of 3 zones: Zona glomerulosa (zg), Zona fasciculata (zf) and Zona reticularis (zr). b: The Zona fasciculata of group I consists of rows of polyhedral cells (spongiocytes) separated by blood capillaries (thin arrows). Spongiocytes appear with acidophilic vacuolated cytoplasm and central rounded vesicular nuclei (thick arrows) and some of these cells are binucleated (curved arrows). c and d: Group II shows disorganization and marked vacuolations of the cells of Zona fasciculata (v). The majority of these cells appear with shrunken dark nuclei (thick arrows). Additionally, mononuclear infiltration (IC), macrophages (wavy arrows), heamorrhage (curved arrows) and blood capillaries (bc) dilatation with disrupted basement membrane are noticed (thin arrow). e: Group III shows almost normal histological appearance except for the presence of few cytoplasmic vacuolations (v), dark nuclei (arrows) and slight capillary dilatation (bc).

[H\&E, x40 (a) and x400 (b, c, d and e)] 

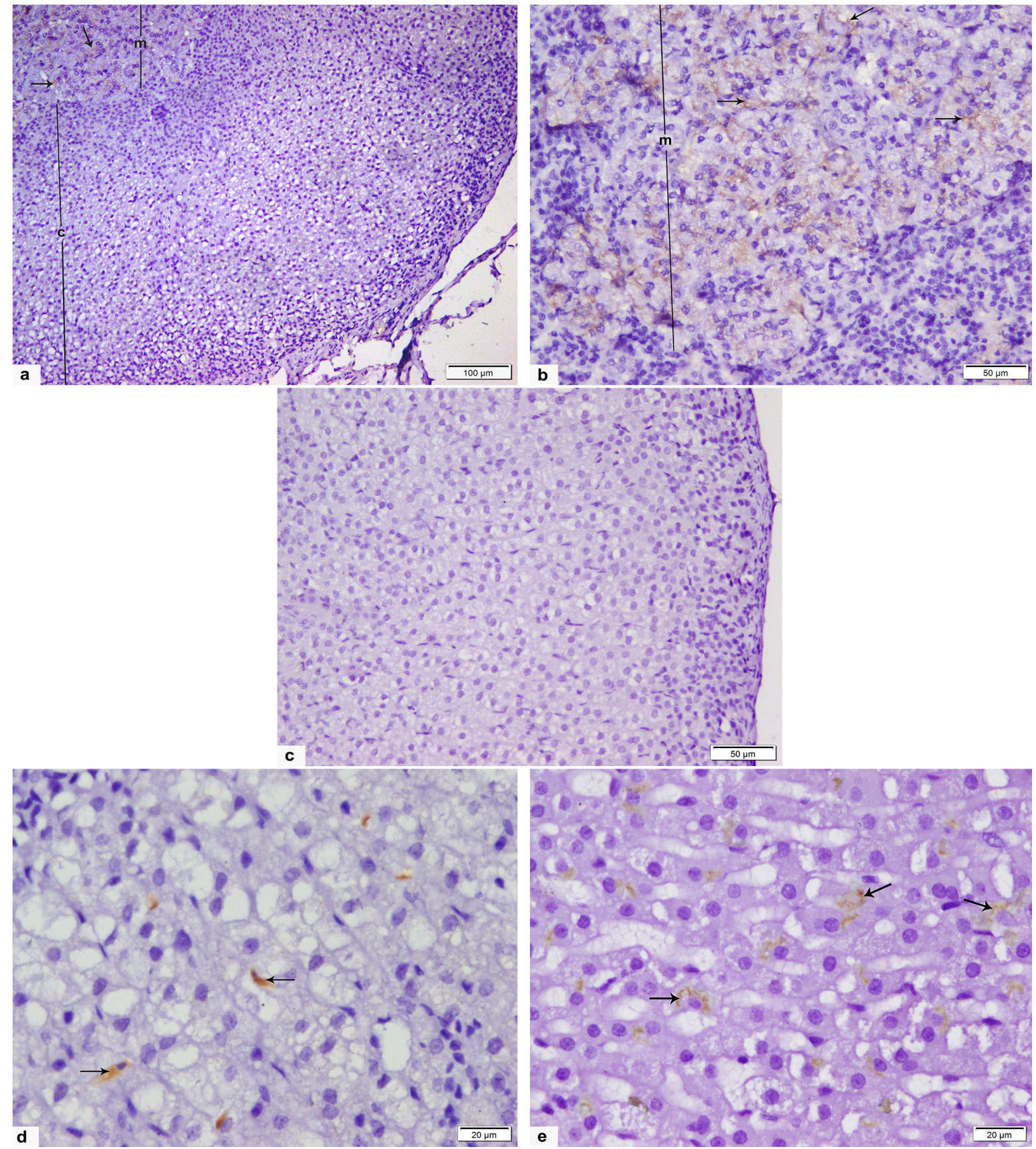

Fig. 3: Photomicrographs of rats' suprarenal gland sections showing: a and b: In control group, negative CD44 immunoreaction in cortex (c) and positive CD44 immunoreaction (arrows) in the cytoplasm of some of the adrenal medulla (m) cells. c: The steroidogenic cells of zona fasciculata of group I show no immunoreaction. d: In group II, few CD44 immunoreaction (arrows) is detected in the Zona fasciculate. e: In group III, multiple cells in the Zona fasciculata appear with positive immunoreaction (arrows).

[Anti-CD44 Immunostaining, x100 (a), x200 (b and c) and x400 (d and e)] 

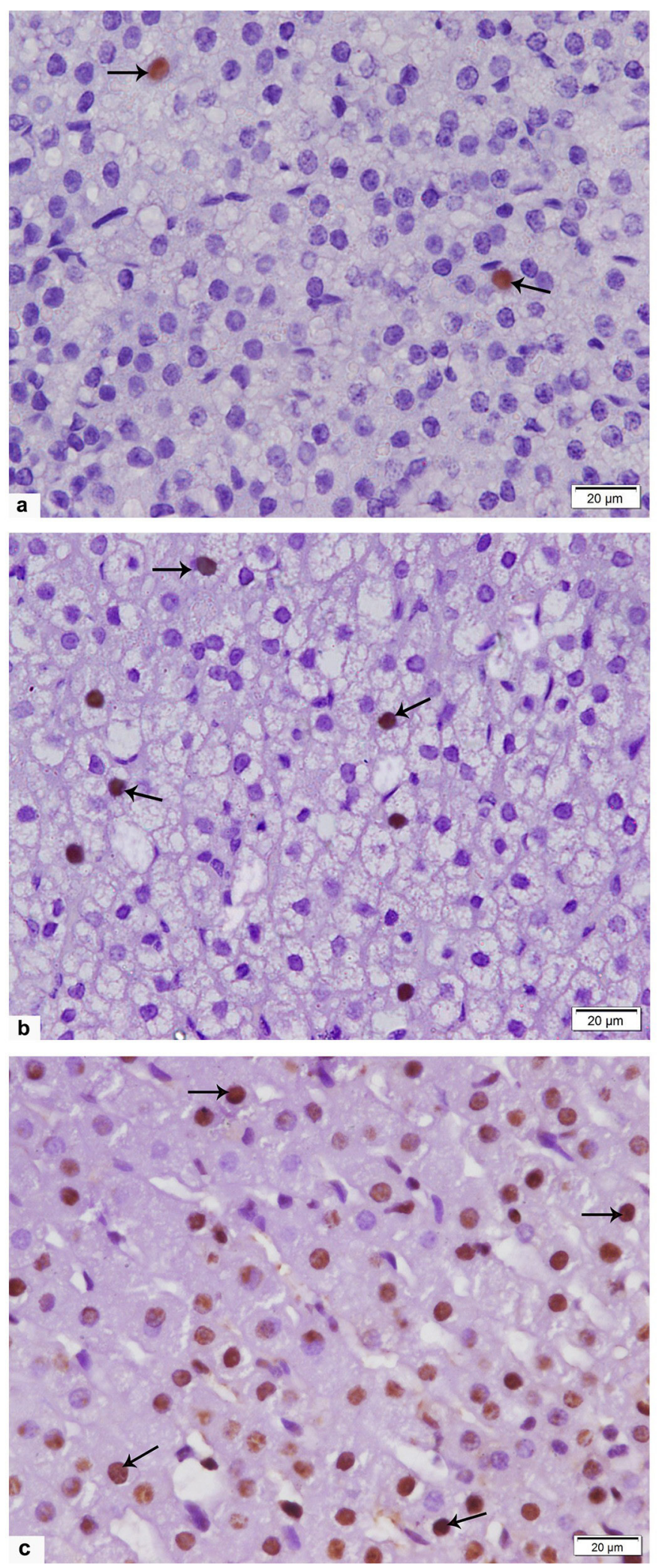

Fig. 4: Photomicrographs of sections in the suprarenal gland of albino rats showing: a: Two Zona fasciculata cells with nuclear immunoreactivity (arrows) in the control group. b: Sections of group II show some cells with positive nuclear immunoreaction (arrows). c: The majority of the Zona fasciculata cells in group III show positive nuclear immunoreaction (arrows).

[Anti-PCNA Immunostaining, x400] 

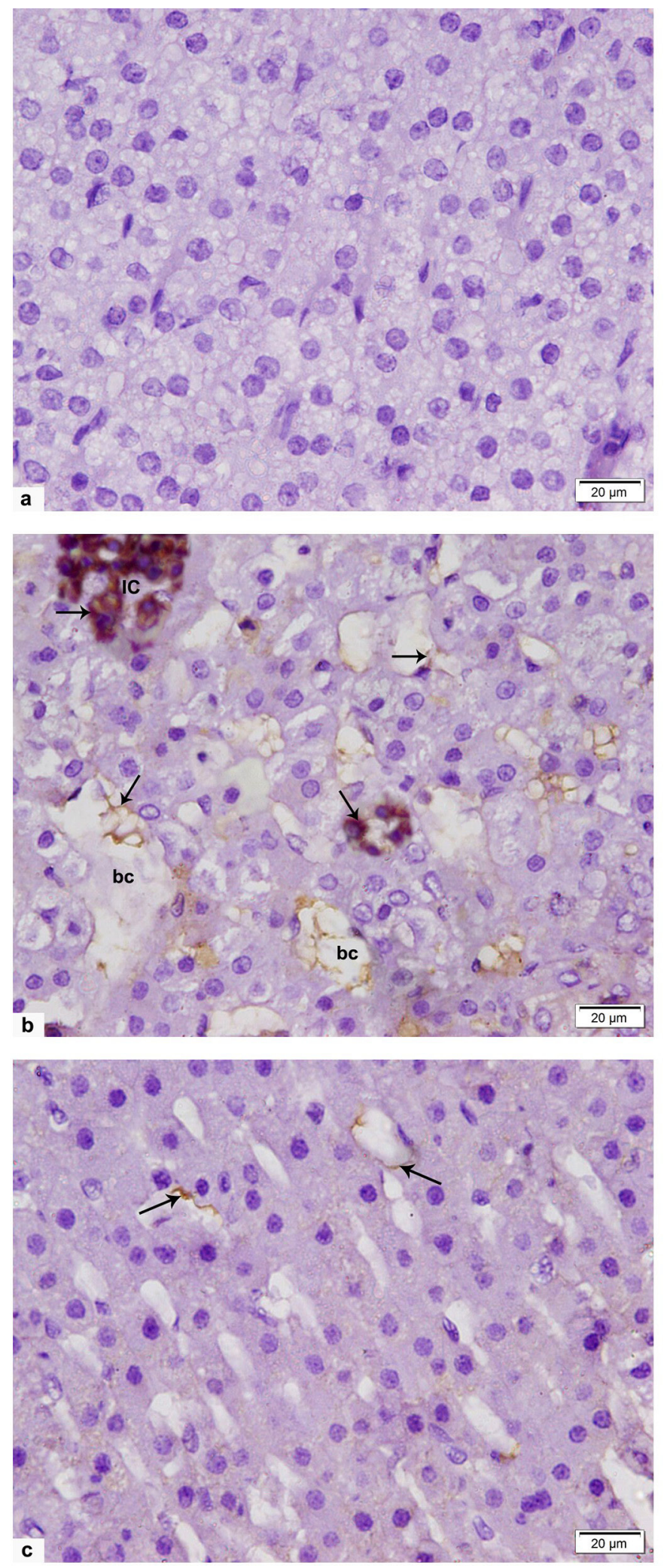

Fig. 5: Photomicrographs of sections in the rats' suprarenal gland showing: a: No immunoreaction in the sections of the control group. b: Group II shows multiple positive immunoreactions (arrows) in the endothelial and the inflammatory cells. c: Group III shows very few endothelial cells with positive immunoreaction (arrows). 


\section{DISCUSSION}

Sepsis is a major global health problem with high mortality rate (up to $25 \%$ ) that was reported to increase to $70 \%$ when sepsis is complicated by septic shock and multiorgan failure ${ }^{[2]}$.

Although the devastating inflammatory reaction accompanying sepsis could be controlled by the release of cortisol (via HPA axis) with its anti-inflammatory and immunomodulatory effects ${ }^{[5]}$, adrenal insufficiency with low cortisol secretion was stated to occur with septicemia and septic shock ${ }^{[7]}$.

Being the main source of cortisol in the body and the most vulnerable zone of the adrenal glands to be affected by sepsis, Zona fasciculata was chosen for this work ${ }^{[22,23]}$.

Moreover, ADMSCs-MVs were preferred for this study rather than ADMSCs themselves although; they have equal reparative effects ${ }^{[1]}$ to avoid its unpleasant effects. Whereas, the mesenchymal stem cells may undergo maldifferentiation and tumor formation ${ }^{[24]}$. In addition, there was an evidence for induction of host immune response to mesenchymal stem cells with limitation of their therapeutic effects, especially in cases of inflammation, due to their expression of MHC-II evoked by the release of inflammatory cytokines ${ }^{[25]}$.

In the present study, single intravenous injection of LPS extracted from E. coli induced inflammatory cell infiltration including macrophages in the Zona fasciculata of the suprarenal cortex. This finding is concomitant with that sepsis is an irresistible inflammatory response characterized by leukocytic infiltration in different organ $\mathbf{s}^{[4]}$ especially, the adrenal glands ${ }^{[1,22]}$.

Additionally, there was significant increase in mean value of TNF- $\alpha$ (a pro-inflammatory cytokine) in the suprarenal homogenates of LPS-group of this work versus the control group. Alike, there was increase in the adrenal glands' levels of cytokines [interleukin-6 (IL-6), interleukin-1 $\beta$ (IL-1 $\beta$ ) and TNF- $\alpha$ ] and chemokines [C-X-C motif ligand 2 (CXCL2) and C-C motif ligand 2 (CCL2)] following septicemia induced by cecal ligation and puncture surgery ${ }^{[1]}$.

Based on that, these chemokines and cytokines were proved to be secreted by the infiltrated immune cells, not by the cells of the suprarenal glands ${ }^{[26]}$. Such chemokines are able to increase the leukocytic infiltration ${ }^{[27]}$. It could be assumed that the immune cell infiltration might be responsible for an exaggerated adrenal inflammatory response in cases of sepsis.

Histological examination of LPS group (group II) of the present study revealed massive cytoplasmic vacuolations in the Zona fasciculata cells. Such finding is consistent with that formerly reported following acute toxicity ${ }^{[23]}$. These vacuolations might be related to the inflammatory infiltration where it was documented that neutrophils produce neutrophil nicotinamide adenine dinucleotide phosphate (NADPH)-oxidase just after activation and trans-endothelial migration. It, consequently, acts on membranous and cytoplasmic compounds forming superoxide anions (O2-) and other reactive oxygen species $(\mathrm{ROS})^{[28]}$. This leads to oxidative stress (OS) due to imbalance between pro-oxidants and anti-oxidants. Moreover, the adrenal steroid synthesizing cells are more susceptible to OS than other cells. These cells use large amount of oxygen in the oxidative reactions, not only for mitochondrial respiration to produce energy but also for steroid synthesis, generating a lot of ROS ${ }^{[29]}$.

In addition, the suprarenal cortical cells have large amount of unsaturated fatty acids in their membranes which could be peroxidized in OS resulting into damage of the cell membranes ${ }^{[30,31]}$. This lipid peroxidation was reported before ${ }^{[22]}$ through documentation of high level of malondialdehyde (MDA) in LPS-treated mice. Such membranous damage could lead to mitochondrial and smooth endoplasmic reticulum (sER) degeneration and swelling ${ }^{[23]}$ that could be manifested by the cytoplasmic vacuolations as detected in the present study.

Another explanation for such cytoplasmic vacuolations was based on that mitochondrial and sER damage were evidenced to be followed by diminished steroidogenesis ${ }^{[23]}$ as they perform crucial roles in glucocorticoid synthesis ${ }^{[32]}$. This in turn increased the lipid droplets (the steroid precursors) that might coalesce together forming large cytoplasmic vacuolations ${ }^{[33]}$.

The blood capillaries in LPS-group of this work showed dilatation and disruption of the basement membrane continuity with extravasated blood and heamorrhage. These findings come in line with those previously stated following toxic injury to the lung ${ }^{[34]}$, the liver ${ }^{[35]}$, the kidney $^{[36]}$, the brain ${ }^{[37]}$ and the adrenal cortex ${ }^{[22,38]}$. Such endothelial damage was suggested to be due to OS mediated by ROS.

The damaged endothelial cells together with macrophages of the inflammatory infiltration were evidenced to produce iNOS in suprarenal gland during sepsis. This iNOS was documented not to be secreted by the adrenal cortical cells in in vivo study and in culture treated with LPS ${ }^{[38]}$. Such finding was enforced by the positive iNOS immunoreaction in both inflammatory and endothelial cells and its negative expression in spongiocytes of group II.

Expression of iNOS during inflammation is followed by overproduction of nitric oxide (NO) which is normally produced from the other isoforms of NOS [neural (nNOS) and endothelial (eNOS) $]^{[39]}$. In adrenal cortex the normal level of NO was documented to be due to eNOS produced by its cells ${ }^{[40]}$. This could be supported in the present study by the presence of a basal level of NO in the control group despite the negative iNOS immunoreaction and its significant increase in LPS-group versus control. 
Bearing in mind that eNOS production in adrenal cortex is markedly reduced 3 hours after LPS treatment ${ }^{[38,40]}$, besides the high vascularity of Zona fasciculata. Thus, the significant increase in NO level in LPS-group versus control group in this work could be contributed to the marked production of iNOS by the damaged endothelial and the infiltrated inflammatory cells.

The excess $\mathrm{NO}$ was shown to react with $\mathrm{O} 2$ - forming peroxynitrate (ONOO-) and other reactive nitrogen species $(\mathrm{RNS})^{[41]}$. Such reaction is initiated by nitrotyrosine (peroxynitrate biomarker in adrenal glands) produced during endotoxemia ${ }^{[22]}$. This reaction was documented to be followed by massive oxidative/nitrative stress with subsequent mitochondrial damage ${ }^{[38]}$, adrenal cellular death and reduced steroidogenesis ${ }^{[42]}$ in addition to more endothelial damage and heamorrhage ${ }^{[1]}$.

Death of the adrenal cortical cells during sepsis was reported to be caused by apoptosis ${ }^{[26]}$. This observation was supported in group II of the current study by the presence of shrunken dark nuclei. It could be explained by the severe oxidative and nitrative stress that could oxidize proteins, lipids, DNA and RNA and induce nitrative protein alterations $^{[41]}$

Severe inflammatory degeneration of the Zona fasciculata cells and reduction of steroidogenesis were suggested to significantly decrease cortisol secretion from these cells ${ }^{[1]}$. Cortisol can modify the metabolism and increase the blood sugar level providing energy for the body in addition to its suppressive effect on the activated immune system and supportive effect on the circulatory system ${ }^{[43]}$. So, low basal cortisol level with loss of its supportive functions and high level of NO (a potent vasodilator) with its marked hypotension and homeostatic instability ${ }^{[4]}$ could result in exaggeration of sepsis.

Such sepsis exaggeration might progress to multi-organ failure and septic shock with increased mortality rate, up to $70 \%{ }^{[2]}$. This striking deterioration was presumed to be the cause of deaths occurred in this study one day following LPS administration. Such assumption was similarly demonstrated before, where massive inflammatory infiltration, heamorrhage and markedly increased proinflammatory cytokines (IL-6, IL- $1 \beta$ and TNF- $\alpha$ ) were detected in the adrenals of the dead mice 24 and 48 hours after cecal ligation and puncture surgery ${ }^{[1]}$.

MV-group of the present work showed that single IV injection of ADMSCs-MVs led to almost normal histological appearance of Zona fasciculata. This curative effect of stem cell-MVs was formerly described in other organs' lesions such as Escherichia coli-induced acute lung injury ${ }^{[14]}$, acute kidney injury ${ }^{[45]}$ and partial hepatectomy ${ }^{[46]}$. They also adjusted neurogenesis and angiogenesis in ischemic stroke ${ }^{[47]}$, kept the endothelial cells against hypoxic injury ${ }^{[48]}$ and avoided pulmonary hypertension induced by hypoxia ${ }^{[49]}$.

MVs effects described in this study could be explained based on that they are liberated from almost all cells (resting and activated) and they have the same effects as the cells from which they originate ${ }^{[30]}$. Thus, ADMSCsMVs have the same surface antigens characteristics of $\mathrm{ADMSCs}^{[50]}$ and can transfer proteins, lipids, mRNA, microRNA, and/or organelles with reparative functions from the stem cells to the injured cells ${ }^{[51]}$. Additionally, the therapeutic paracrine effects of mesenchymal stem cells were proved to be due to the liberated MVs, not due to the secreted trophic factors. This was evidenced by absence of the therapeutic influences of the stem cells media after removal of the $\mathrm{MVs}^{[49]}$. Further support to this proof was stated by other authors where they discovered that the therapeutic effect of the stem cells supernatant caused by particles more than $100 \mathrm{kDa}$ (the exosomes released by the stem cells) and not due to stem cells trophic factors which are less than $100 \mathrm{kDa}^{[16]}$.

Accordingly, the demonstrated homing of the PKH26 labelled ADMSCs-MVs to the zona fasciculata in MVgroup and their absence in the control subgroup IC could be enlightened. This finding is similarly reported in former studies where MVs originating from stem cells were detected in the acutely injured kidney ${ }^{[13]}$ and lung ${ }^{[11]}$.

Such ADMSCs-MVs homing, similar to that of mesenchymal stem cells, was evidenced to be due to CD44 receptors expressed on MVs surface. The MVs uptake, internalization and effects are initiated by binding of these receptors to L-selectin and osteopontin ligands overexpressed on the injured cells. So, pretreatment of MVs with CD44 blocking antibody led to loss of their curative effects $^{[14]}$. This binding is followed by endocytosis or membrane fusion to incorporate the MVs into the injured cells to start their therapeutic actions ${ }^{[52]}$. Based on that, the significant increase in the mean number of CD44 immunopositive cells detected in MV-group versus LPS-group could be assumed to be due to homing and internalization of the injected ADMSCs-MVs.

Interestingly, CD44 positive immunoreactivity was widely spread in the adrenal medulla cells in the control group of this work and completely absent in the cells of the adrenal cortex. This finding is concomitant with that previously reported ${ }^{[53]}$ where it was explained by that CD44 is expressed by cells of neural crest origin. Furthermore, the adrenal medulla originates from neuroectoderm while, the adrenal cortex is mesodermal in origin. However, the demonstrated few CD44 positive cells in LPS-group was presumably due to homing of the endogenous adrenal stem cells to the site of lesion in a trial to preserve the lesioned cells.

Stem cell-MVs were proved to downregulate chemokine (C-X3-C motif) ligand 1 (CX3CL1) protein, a potent chemo-attractant factor for macrophages, present on the endothelial cells in cases of renal ischemic-reperfusion injury. Therefore, stem cell-MVs could decrease monocytes transmigration across the endothelium ${ }^{[15]}$. Similar MVs effect was presumed to happen in MV-group of this work 
explaining the absence of the inflammatory infiltration in this group.

Additionally, stem cell-MVs were shown to reprogram monocytes/macrophage system from M1 (proinflammatory phenotype) to M2 (anti-inflammatory phenotype $)^{[54]}$. This occurred through transfer of mRNA of COX-2 (the main enzyme in PGE2 synthesis) from MVs to monocytes increasing prostaglandin E2 (PGE2) level[55]. The increased PGE2 acts on EP2 and EP4 (PGE2 receptors) present on monocytes and macrophages, increasing their production of anti-inflammatory cytokines such as interleukin-10 (IL-10) ${ }^{[56]}$. Such immunomodulatory reprogramming was supported in the current study by the significant increase in the mean COX-2 level in group III compared to group II which showed non-significant increase than group I. Moreover, in MV-group, there was significant decrease in TNF- $\alpha$ and NO levels and the mean area percent of iNOS (M1, pro-inflammatory marker) versus LPS-group and non-significant increase of TNF- $\alpha$ and NO levels versus control group.

In addition, ADMSCs-MVs were reported to decrease the release of ROS from the activated neutrophils ${ }^{[16]}$. Consequently, the oxidative/nitrative stress was suggested to be lowered with reduction of mitochondrial and sER damage and apoptotic cell death ${ }^{[45]}$. This suggestion was reinforced in this work by the presence of very few cytoplasmic vacuolations, pyknotic nuclei and weak positive iNOS immunoreaction in few endothelial cells.

Furthermore, MV-group showed significant increase in the mean number of PCNA immune-positive cells versus LPS-group. This could be elucidated by the ability of stem cell-MVs to increase the proliferative capacity and the apoptotic resistance of the remaining mature cells ${ }^{[57]}$ through transfer of their high contents of proliferation genes and proteins ${ }^{[58]}$. In addition, they could reestablish the ATP level and the metabolic activities in the injured cells ${ }^{[14]}$ through transmission of the metabolic principle enzymes ${ }^{[59]}$ and mRNA for mitochondrial genes ${ }^{[60]}$ or even via transfer of the mitochondria themselves ${ }^{[61]}$.

Depending on that explanation, PCNA positive nuclei in LPS-group was suggested to be due to endogenous stem cell-MVs.

\section{CONCLUSION}

LPS-induced sepsis resulted in marked inflammatory degeneration of adrenal gland Zona fasciculata which might be followed by reduction of cortisol production with subsequent progression to septic shock and multi-organ failure. These degenerative changes could be improved by single IV injection of ADMSCs-MVs, mostly through their ability to transfer proteins, mRNA, microRNA and/or organelles with reparative functions from the stem cells to the injured tissues upon their direct contact.

\section{CONFLICT OF INTEREST}

There are no conflicts of interest.

\section{REFERENCES}

1. Jennewein C, Tran N, Kanczkowski W, Heerdegen L, Kantharajah A, Dröse S, Bornstein S, Scheller B and Zacharowski K: Mortality of Septic Mice Strongly Correlates With Adrenal Gland Inflammation in Crit Care Med (2016) 44:e190-e199.

2. Angus DC and vanderPoll T: Severe sepsis and septic shock in N. Engl.J.Med (2013) 369: 2062-2063.

3. Patel GP and Balk RA: Systemic steroids in severe sepsis and septic shock in Am J Respir Crit Care Med (2012) 185: 133-139.

4. Nathan $\mathrm{C}$ and Ding A: Nonresolving inflammation in Cell (2010)140: 871-882.

5. Kanczkowski W, Sue M, Zacharowski K, Reincke $\mathrm{M}$ and Bornstein SR: The role of adrenal gland microenvironment in the HPA axis function and dysfunction during sepsis in Mol Cell Endocrinol (2015) 408:241-248.

6. Bosmann M, Meta F, Ruemmler R, Haggadone MD, Sarma JV, Zetoune FS and Ward PA: Regulation of IL-17 family members by adrenal hormones during experimental sepsis in mice in Am J Pathol (2013) 182: 1124-1130.

7. Batzofin, BM, Sprung CL and Weiss YG: The use of steroids in the treatment of severe sepsis and septic shock in Best Pract.Res.Clin.Endocrinol. Metab (2011) 25: 735-743.

8. Marik PE, Pastores SM, Annane D, Meduri GU, Sprung CL, Arlt W, Keh D, Briegel J, Beishuizen A, Dimopoulou I, Tsagarakis S, Singer M, Chrousos GP, Zaloga G, Bokhari $F$ and Vogeser $\mathrm{M}$ : Recommendations for the diagnosis and management of corticosteroid insufficiency in critically ill adult patients: consensus statements from an international task force by the American College of Critical Care Medicine in Crit. Care Med (2008) 36: 1937-1949.

9. Dellinger RP, Levy MM, Rhodes A, Annane D, Gerlach H, Opal SM, Sevransky JE, Sprung CL, Douglas IS, Jaeschke R, Osborn TM, Nunnally ME, Townsend SR, Reinhart K, 
Kleinpell RM, Angus DC, Deutschman CS, Machado FR, Rubenfeld GD, Webb SA, Beale RJ, Vincent JL, Moreno R; Surviving Sepsis Campaign Guidelines Committee including the Pediatric Subgroup: Surviving sepsis campaign: international guidelines for management of severe sepsis and septic shock: 2012 in Crit Care Med (2013) 41(2): 580-637.

10. Ratajczak MZ: The emerging role of microvesicles in cellular therapies for organ/tissue regeneration in Nephrol Dial Transplant (2011) 26: 1453-1456.

11. Zhu $\mathrm{Y}$, Feng $\mathrm{X}$, Abbott J, Fang $\mathrm{X}$, Hao $\mathrm{Q}$, Monsel A, Qu J, Matthay MA and Lee JW: Human Mesenchymal Stem Cell Microvesicles for Treatment of E.coli Endotoxin-Induced Acute Lung Injury in Mice in Stem Cells (2014) 32(1): 116-125.

12. Mause SF and Weber C: Microparticles: protagonists of a novel communication network for intercellular information exchange in Circ Res (2010) 107: 1047-1057.

13. Bruno S, Grange C, Deregibus MC, Calogero RA, Saviozzi S, Collino F, Morando L, Busca A, Falda M, Bussolati B, Tetta C and Camussi G: Mesenchymal stem cell-derived microvesicles protect against acute tubular injury in $\mathrm{J}$ Am Soc Nephrol (2009) 20: 1053-1067.

14. Monsel A, Zhu Y, Gennai S, Hao Q, Hu S, Rouby J, Rosenzwajg M, Matthay MA, and Lee JW: Therapeutic Effects of Human Mesenchymal Stem Cell-derived Microvesicles in Severe Pneumonia in Mice in American Journal of Respiratory and Critical Care Medicine (2015) 192 (3): 324-336.

15. Zou X, Zhang G, Cheng Z, Yin D, Du T, Ju G, Miao S, Liu G, Lu M and Zhu Y: Microvesicles derived from human Wharton's Jelly mesenchymal stromal cells ameliorate renal ischemia-reperfusion injury in rats by suppressing CX3CL1 in Stem Cell Research \& Therapy (2014) 5(2): 40-53.

16. Mumaw JL, Schmiedt CW, Breidling S, Sigmund A, Norton NA, Thoreson M, Peroni JF and Hurley DJ: Feline mesenchymal stem cells and supernatant inhibit reactive oxygen species production in cultured feline neutrophils in Research in Veterinary Science (2015)103: 60-69.

17. Shin S, Kim Y, Jeong S, Hong S, Kim I, Lee W and Choi S: The Therapeutic Effect of Human Adult Stem Cells Derived from Adipose Tissue in Endotoxemic Rat Model in Int. J. Med. Sci (2013) 10(1): 8-18.
18. El-Akabawy G and El-Kholy W: Neuroprotective effect of ginger in the brain of streprozotocininduced diabetic rats in Ann Anat (2014) 169: 119-128.

19. Kiernan J. Histological and histochemical methods: theory and practice. 3rd ed. London, New York and New Delhi: Arnold Publisher; 2001. pp. 111-162.

20. Bancroft J, Gamble M. Theory and practice of histological techniques. Staining methods. 7th ed. Edinburgh, London, Madrid, Melbourne, New York, and Tokyo: Churchill Livingstone; 2008. pp. 263-325.

21. Emsley R, Dunn G, White IR. Mediation and moderation of treatment effects in randomised controlled trials of complex interventions. Stat Methods Med Res 2010; 19: 237-270.

22. Duan G, Wang C, Liu Y, Yu Q, Tang X, Ni X and Zhu X: Resveratrol alleviates endotoxemiaassociated adrenal insufficiency by suppressing oxidative/nitrative stress in Endocrine journal (2016) 63 (6): 569-580.

23. Rosol TJ, Yarrington JT, Latendresse $\mathrm{J}$ and Capen CC: Adrenal Gland: Structure, Function, and Mechanisms of Toxicity in Toxicol Pathol (2001) 29(1): 41-48.

24. Thirabanjasak D, Tantiwongse $\mathrm{K}$ and Thorner PS: Angiomyeloproliferative lesions following autologous stem cell therapy in J Am Soc Nephrol (2010) 21: 1218-22.

25. Schu, S., Nosov,M., O'Flynn, L., Shaw, G., Treacy, O., Barry, F.,Murphy, M., O'Brien, T., and Ritter, $\mathrm{T}$ : Immunogenicity of allogeneic mesenchymal stemcells in J. Cell. Mol. Med (2012) 16: 2094-2103.

26. Kanczkowski W, Alexaki VI, Tran N, Großklaus S, Zacharowski K, Martinez A, Popovics P, Block NL, Chavakis T, Schally AV and Bornstein SR: Hypothalamo-pituitary and immunedependent adrenal regulation during systemic inflammation in Proc Natl Acad Sci U S A (2013) 110: 14801-14806.

27. Ramnath RD, Ng SW, Guglielmotti A and Bhatia $\mathrm{M}$ : Role of MCP-1 in endotoxemia and sepsis in Int Immunopharmacol (2008) 8: 810-818.

28. Ciz M, Denev P, Kratchanova M, Vasicek O, Ambrozova $G$ and Lojek A: Flavonoids inhibit the respiratory burst of neutrophils inmammals 
in Oxidative Med. Cell. Longev (2012) 2012: 181295.

29. Prasad R, Kowalczyk JC, Meimaridou E, Storr HL and Metherell LA: Oxidative stress and adrenocortical insufficiency in $\mathbf{J}$ Endocrinol (2014) 221: R63-73.

30. Tetta C, Bruno S, Fonsato V, Deregibus MC and Camussi G: The role of microvesicles in tissue repair in Organogenesis (2011) 7(2): 105-115.

31. Wang CN, Duan GL, Liu YJ, Yu Q, Tang XL, Zhao W, Li XH, Zhu XY and Ni X: Overproduction of nitric oxide by endothelial cells and macrophages contributes to mitochondrial oxidative stress in adrenocortical cells and adrenal insufficiency during endotoxemia in Free Radic Biol Med (2015) 83: 31-40.

32. Jefcoate C: High-flux mitochondrial cholesterol trafficking, a specialized function of the adrenal cortex in J. Clin.Invest (2002) 110: 881-890.

33. Latendresse JR, Brooks CL and Capen CC: Pathologic effects of butylated triphenyl phosphatebased hydraulicuid and tricresyl phosphate on the adrenal gland, ovary, and testis in the Fischer-344 rat in Toxicol Pathol (1994) 22: 341-352.

34. Mannam P, Zhang X, Shan P, Zhang Y, Shinn AS and Lee PJ: Endothelial MKK3 is a critical mediator of lethal murine endotoxemia and acute lung injury in J. Immunol (2013)190: 1264-1275.

35. La Mura V, Pasarin M, Rodriguez-Vilarrupla A, Garcia-Pagan JC, Bosch J and Abraldes JG: Liver sinusoidal endothelial dysfunction after LPS administration: a role for inducible-nitric oxide synthase in J. Hepatol (2014) 61(6): 1321-1327.

36. Xu C, Chang A, Hack BK, Eadon MT, Alper SL and Cunningham PN: TNF- mediated damage to glomerular endothelium is an important determinant of acute kidney injury in sepsis in Kidney Int (2014) 85: 72-81.

37. Hughes CG, Morandi A, Girard TD, Riedel B, Thompson JL, Shintani AK, Pun BT, Ely EW and Pandharipande PP: Association between endothelial dysfunction and acute brain dysfunction during critical illness in Anesthesiology (2013) 118: 631-639.

38. Wang CN, Duan GL, Liu YJ, Yu Q, Tang XL, Zhao W, Li XH, Zhu XY and Ni X: Overproduction of nitric oxide by endothelial cells and macrophages contributes to mitochondrial oxidative stress in adrenocortical cells and adrenal insufficiency during endotoxemia in Free Radic Biol Med (2015) 83: 31-40.

39. Wang L, Taneja R, Razavi HM, Law C, Gillis C and Mehta S: Specific role of neutrophil inducible nitric oxide synthase in murine sepsis-induced lung injury in vivo in Shock (2012) 37: 539-547.

40. Kanczkowski W, Chatzigeorgiou A, Samus M, Tran N, Zacharowski K, Chavakis T and Bornstein SR: Characterization of the LPS-induced inflammation of the adrenal gland in mice in Mol. Cell. Endocrinol (2013) 371: 228-235.

41. Roberts RA, Laskin DL, Smith CV, Robertson FM, Allen EM, Doorn JA and Slikker W: Nitrative and oxidative stress in toxicology and disease in Toxicol Sci (2009) 112: 4-16.

42. Wang WZ, Fang XH, Williams SJ, Stephenson LL, Baynosa RC, Khiabani KT and Zamboni WA: Elimination of Reperfusion-Induced Microcirculatory Alterations In Vivo by AdiposeDerived Stem Cell Supernatant without AdiposeDerived Stem Cells in Plast. Reconstr. Surg (2015) 135(4): 1056-1064

43. Marik PE and Zaloga GP: "Adrenal insufficiency in the critically ill: a new look at an old problem" in Chest (2002) 122 (5): 1784-1796.

44. Fink MP and Warren HS: Strategies to improve drug development for Sepsis in Nat Rev Drug Discov (2014) 13: 741-758.

45. Bruno S, Grange C, Collino F, Deregibus MC, Cantaluppi V, Biancone L, Tetta C and Camussi G: Microvesicles derived from mesenchymal stem cells enhance survival in a lethal model of acute kidney injury in PLoS One (2012)7(3): e33115.

46. Herrera MB, Fonsato V, Gatti S, Deregibus MC, Sordi A, Cantarella D, Calogero R, Bussolati B, Tetta C and Camussi G: Human liver stem cell-derived microvesicles accelerate hepatic regeneration in hepatectomized rats in $\mathrm{J}$ Cell Mol Med (2010) 14(6b): 1605-1618.

47. Xin H, Li Y, Cui Y, Yang JJ, Zhang ZG and Chopp M: Systemic administration of exosomes released from mesenchymal stromal cells promote functional recovery and neurovascular plasticity after stroke in rats in J Cereb Blood Flow Metab (2013) 33: 1711-1715.

48. Wang J, Chen S, Ma X, Cheng C, Xiao X, Chen J, Liu S, Zhao B and Chen Y: Effects of endothelial 
progenitor cell-derived microvesicles on hypoxia/ reoxygenation-induced endothelial dysfunction and apoptosis in Oxid Med Cell Longev (2013) 2013: 572729 .

49. Lee C, Mitsialis SA, Aslam M, Vitali SH, Vergadi E, Konstantinou G, Sdrimas K, FernandezGonzalez A and Kourembanas S: Exosomes mediate the cytoprotective action of mesenchymal stromal cells on hypoxia-induced pulmonary hypertension in Circulation (2012) 126: 2601-11.

50. Peng Y, Xuan M, Zou J, Liu H, Zhuo Z, Wan Y, Cheng B: Freeze-Dried Rat Bone Marrow Mesenchymal Stem Cell Paracrine Factors: A Simplified Novel Material for Skin Wound Therapy in Tissue Eng Part A (2015) 21: 1036-1046.

51. Ratajczak MZ: The emerging role of microvesicles in cellular therapies for organ/tissue regeneration in Nephrol Dial Transplant (2011) 26: 1453-1456.

52. Raposo $\mathrm{G}$ and Stoorvogel W: Extracellular vesicles: exosomes, microvesicles, and friends in J Cell Biol (2013) 200: 373-383.

53. Barshack I, Goldberg I, Nass D, Olchovsky D and Kopolovic J: CD44 expression in normal adrenal tissue and adrenal tumours in Clin Pathol (1998) 51(1): 52-54.

54. Li JW and $\mathrm{Wu} \mathrm{X:} \mathrm{Mesenchymal} \mathrm{stem} \mathrm{cells}$ ameliorate LPS-induced acute lung injury through KGF promoting alveolar fluid clearance of alveolar type II cells in European Review for Medical and Pharmacological Sciences (2015) 19: 2368-2378.

55. Robbins PD and Morelli AE: Regulation of immune responses by extracellular vesicles in Nat Rev Immunol (2014)14: 195-208.

56. Németh K, LeelahavanichkulA, Yuen PS, Mayer B,
Parmelee A, Doi K, Robey PG, Leelahavanichkul K, Koller BH, Brown JM, Hu X, Jelinek I, Star RA and Mezey E: Bone marrow stromal cells attenuate sepsis via prostaglandin E2-dependent reprogramming of host macrophages to increase their interleukin-10 production in Nat Med (2009) 15(1): 42-49.

57. Collino F, Deregibus MC, Bruno S, Sterpone L, Aghemo $\mathrm{G}$, Viltono L, Tetta $\mathrm{C}$ and Camussi $\mathrm{G}$ : Microvesicles derived from adult human bone marrow and tissue specific mesenchymal stem cells shuttle selected pattern of miRNAs in PLoS One (2010) 5(7): e11803.

58. Kim HS, Choi DY, Yun SJ, Choi SM, Kang JW, Jung JW, Hwang D, Kim KP and Kim DW: Proteomic analysis of microvesicles derived from human mesenchymal stem cells in J Proteome Res (2012) 11: 839-849.

59. Arslan F, Lai RC, Smeets MB, Akeroyd L, Choo A, Aguor ENE, Timmers L, van Rijen HV, Doevendans PA, Pasterkamp G, Lim SK and de Kleijn DP: Mesenchymal stem cellderived exosomes increase ATP levels, decrease oxidative stress and activate PI3K/Akt pathway to enhance myocardial viability and prevent adverse remodeling after myocardial ischemia/reperfusion injury in Stem Cell Res (2013) 10: 301-312.

60. Lai RC, Yeo RWY, Tan KH and Lim SK: Mesenchymal stem cell exosome ameliorates reperfusion injury through proteomic complementation in Regen Med (2013) 8: 197-209.

61. Islam MN, Das SR, Emin MT, Wei M, Sun L, Westphalen K, Rowlands DJ, Quadri SK, Bhattacharya S and Bhattacharya J: Mitochondrial transfer from bone-marrow-derived stromal cells to pulmonary alveoli protects against acute lung injury in Nat Med (2012)18: 759-765. 
الملخص العربى

\section{هل الحويصلات الدقيقة المستمدة من الخلايا الجذعية الوسيطة الدهنية لايها الإمكانية العلاجية

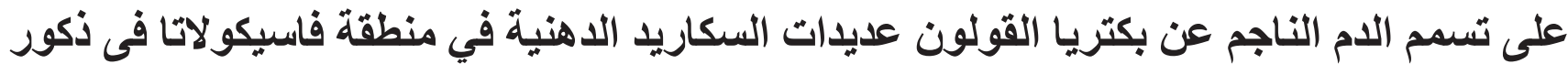

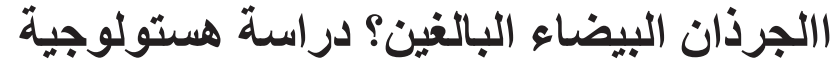

\section{عبيز ابراهيم عمر و الشيماء جمال أبو الخير}

\section{قسم علم الأنسجة الطبيه و بيولوجيا الخليه ، كلية الطب، جامعة القاهرة ، القاهرة ، مصر}

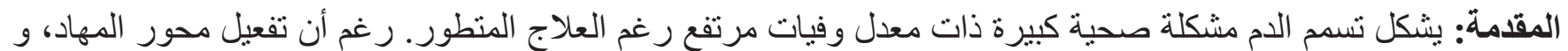

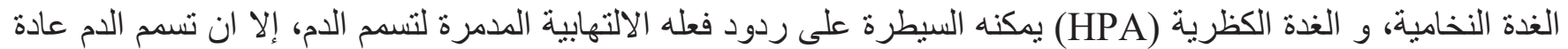

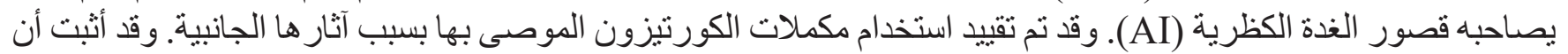

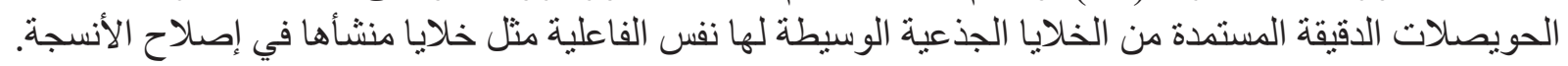

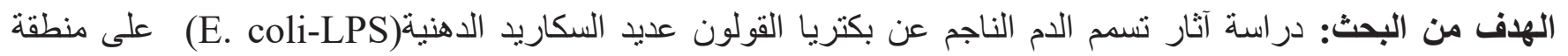

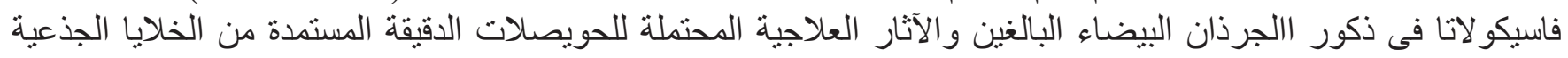
الوسبطة الدهنية (ADMSCs-MVs).

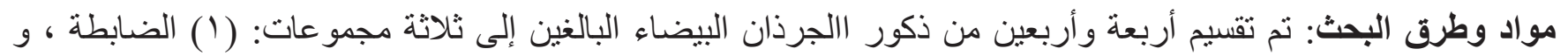

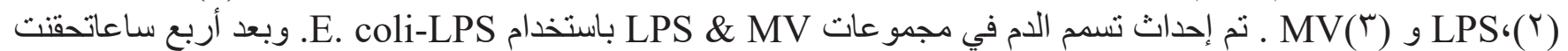

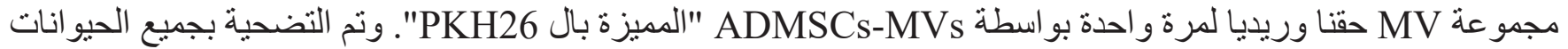

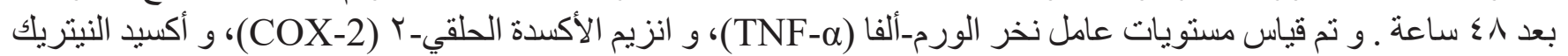

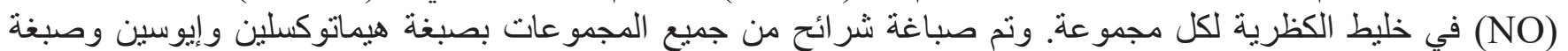

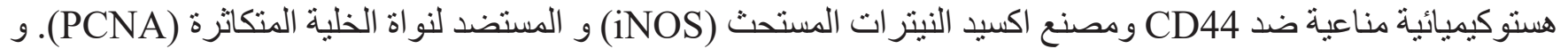

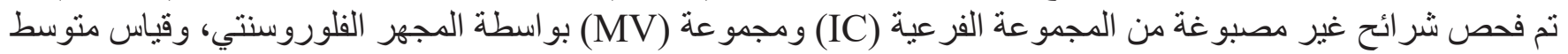

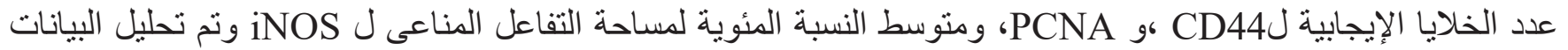

إحصائيا.

النتائج: أظهرت مجموعة LPS وجودغير ناجين (ع باساعة بعد حقن LPS) وناجين مع ملامح الأضرار الالتهابية لمنطقة

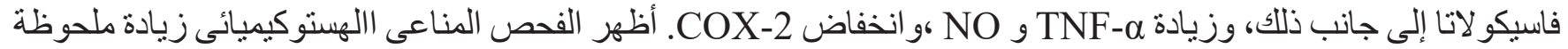

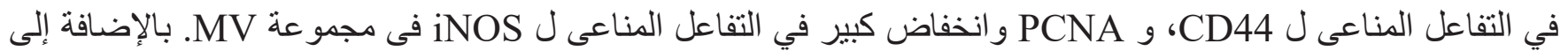

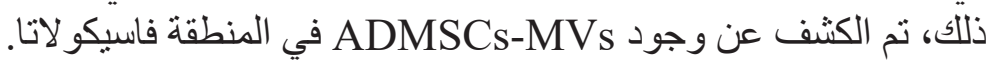

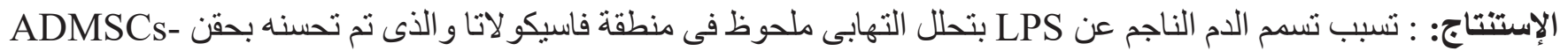

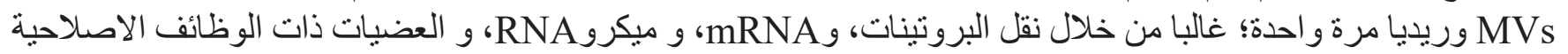
من ADMSCs إلى الأنسجة المصابة. 